\title{
DNA Repair Expression Profiling to Identify High-Risk Cytogenetically Normal Acute Myeloid Leukemia and Define New Therapeutic Targets
}

\author{
Ludovic Gabellier ${ }^{1,2,3}$, Caroline Bret ${ }^{2,4,5}$, Guillaume Bossis ${ }^{3,6}\left(\mathbb{D}\right.$, Guillaume Cartron ${ }^{1,2,3}$ and \\ Jérôme Moreaux 2,4,5,7,*(D) \\ 1 Département d'Hématologie Clinique, CHU Montpellier, University of Montpellier, 34395 Montpellier, \\ France; ludovic.gabellier@igmm.cnrs.fr (L.G.); g-cartron@chu-montpellier.fr (G.C.) \\ 2 UFR de Médecine, University of Montpellier, 34003 Montpellier, France; c-bret@chu-montpellier.fr \\ 3 Institut de Génétique Moléculaire de Montpellier (IGMM), University of Montpellier, CNRS, \\ 34090 Montpellier, France; guillaume.bossis@igmm.cnrs.fr \\ 4 CHU Montpellier, Department of Biological Hematology, 34395 Montpellier, France \\ 5 Institute of Human Genetics, IGH, CNRS, University of Montpellier, 34395 Montpellier, France \\ 6 Equipe Labellisée Ligue Contre le Cancer, 75013 Paris, France \\ 7 Institut Universitaire de France (IUF), 75005 Paris, France \\ * Correspondence: jerome.moreaux@igh.cnrs.fr
}

Received: 3 September 2020; Accepted: 2 October 2020; Published: 6 October 2020

Simple Summary: Acute myeloid leukemia (AML) is the second most frequent type of adult leukemias. Cytogenetically normal acute myeloid leukemias represent about $50 \%$ of total adult $\mathrm{AML}$, exhibit no chromosomal abnormalities, and present high heterogeneity regarding the clinical outcome. Deregulation of DNA repair mechanisms is involved in the adaptation of cancer cells to replicative stress and resistance to genotoxic agents. We investigate the prognostic value of genes related to the major DNA repair pathways. The data reveals specific patterns of gene expression in CN-AML that have prognostic value. Combined with NPM1 and FLT3 mutational status, our gene expression-based DNA repair score might be used as a biomarker to predict outcomes for patients with CN-AML. DNA repair score has the potential to identify CN-AML patients whose tumor cells are dependent on specific DNA repair pathways to design new targeted therapies.

Abstract: Cytogenetically normal acute myeloid leukemias (CN-AML) represent about $50 \%$ of total adult AML. Despite the well-known prognosis role of gene mutations such as NPM1 mutations of FLT3 internal tandem duplication (FLT3-ITD), clinical outcomes remain heterogeneous in this subset of AML. Given the role of genomic instability in leukemogenesis, expression analysis of DNA repair genes might be relevant to sharpen prognosis evaluation in CN-AML. A publicly available gene expression profile dataset from two independent cohorts of patients with CN-AML were analyzed (GSE12417). We investigated the prognostic value of 175 genes involved in DNA repair. Among these genes, 23 were associated with a prognostic value. The prognostic information provided by these genes was summed in a DNA repair score, allowing to define a group of patients $(n=87 ; 53.7 \%)$ with poor median overall survival (OS) of 233 days (95\% CI: 184-260). These results were confirmed in two validation cohorts. In multivariate Cox analysis, the DNA repair score, NPM1, and FLT3-ITD mutational status remained independent prognosis factors in CN-AML. Combining these parameters allowed the identification of three risk groups with different clinical outcomes in both training and validation cohorts. Combined with NPM1 and FLT3 mutational status, our GE-based DNA repair score might be used as a biomarker to predict outcomes for patients with CN-AML. DNA repair score has the potential to identify CN-AML patients whose tumor cells are dependent on specific DNA repair pathways to design new therapeutic avenues. 
Keywords: acute myeloid leukemia; normal karyotype; DNA repair; risk score; precision medicine

\section{Introduction}

Acute myeloid leukemia (AML) is the second most frequent type of adult leukemias. When analyzed with conventional cytogenetics, about $40-50 \%$ of AML exhibits no chromosomal abnormalities and are defined as "cytogenetically normal AML" (CN-AML) [1]. Recurrently mutated genes in CN-AML were identified, such as NPM1, signal transduction genes (FLT3), or myeloid transcription factor genes (CEBPA, RUNX1) [2]. Based on the presence, absence, and allelic ratio of these mutations, $\mathrm{CN}$-AML may be classified in favorable, intermediate, or adverse prognosis, illustrating the high heterogeneity of clinical outcomes in this AML subset [3]. Yet, a wide diversity of gene mutations occurring in CN-AML were revealed by deep sequencing techniques, such as mutations of DNA modification, cohesin or tumor-suppressor genes, suggesting the wide heterogeneity of molecular mechanisms involved in leukemogenesis [4-6].

Even if the study of the mutational landscape by new DNA sequencing technologies demonstrated a low mutation frequency in AML compared to other cancers [7], genomic instability remains a well-described leukemogenesis mechanism, illustrated by the high frequency of AML with non-random cytogenetics abnormalities or with complex karyotype [8,9]. Therefore, the role of DNA damage response (DDR) in the AML field has been widely studied. Polymorphic variants of genes involved in several DNA repair pathways had been associated with the onset of AML, such as XPD-Lys751Gln, involved in the nucleotide excision repair (NER) mechanism [10]. Recurrent AML fusion transcripts such as RUNX1-RUNX1T1 or PML-RARA has also been demonstrated to downregulate the expression of genes implied in DDR [11-14]. Moreover, children or young adults AML are often associated with hereditary diseases due to DNA repair gene mutations, such as Fanconi disease [15], Bloom syndrome, or Werner syndrome [16]. Finally, dysregulation in DDR also contributes to increased resistance to conventional chemotherapy by several mechanisms, such as paradoxically increased expression of DDR or cell cycle check-point genes [17-19].

FLT3 and NPM1 have also been shown to play a role in the DNA damage response in AML. FLT3-ITD mutations, occurring in about $20-25 \%$ of CN-AML, leads to constitutive activation of FLT3 and therefore confers a growth advantage to leukemic cells. Several studies showed that the level of reactive oxygen species (ROS) was increased in FLT3-ITD mutated AML cells and correlated with high levels of double-strand break (DSB) and lower efficiency of non-homologous end joining (NHEJ) repair pathway [20]. Moreover, the use of tyrosine kinase inhibitors may reduce both ROS and DSB levels, and increase DNA repair efficiency, overcoming the chemo-resistance of these cells $[20,21]$. Other mechanisms have been suggested to explain the role of FLT3-ITD in DNA damages and acquired drug resistance of AML cells, such as telomere-related genome instability [22], or paradoxical up-regulation of RAD51 [23]. NPM1 is the most commonly mutated gene in CN-AML, with more than 50 described mutations. The prognostic significance of these mutations and co-mutations in other genes has been widely studied [24]. The role of NPM1 in DNA damage response and maintenance of genome stability is less clear. Nevertheless, NPM1 is involved in the regulation of centrosome duplication during the cell cycle [25] or is recruited in its phosphorylated form (NPM1-pT199) on DSB foci, even if its role in DSB repair remains discussed [26]. NPM1 is also involved in the regulation of key DNA repair factors, such as APEX1 or TP53 $[27,28]$. Therefore, NPM1 mutations in AML result in APEX1 abnormal cytoplasmic accumulation, and impaired base excision repair (BER) activity [29], potentially explaining a chemotherapy improved response in NPM1-mutated AML.

In the current study, we investigate the prognostic value of genes related to the major DNA repair pathways. The data reveals specific patterns of gene expression in CN-AML that have prognostic value. Therefore, the expression analysis of DNA repair genes might be relevant in the context of CN-AML to sharpen prognosis evaluation of this heterogeneous AML subset. 


\section{Results}

\subsection{Linking Expression of DNA Repair Genes and AML Patient Overall Survival}

Considering the important role of DNA repair in drug resistance and adaptation to replication stress in cancer cells, we first aimed to identify the DNA repair genes associated with overall survival in CN-AML. A list set of 175 genes involved in six major DNA repair pathways-ER, NER, mismatch repair (MMR), homologous recombination repair (HRR), NHEJ, and Fanconi (FANC) pathways—defined using the REPAIRtoire database (http://repairtoire.genesilico.pl) and review of the literature (Table S1). Using the MaxStat R function (https://cran.r-project.org/web/packages/maxstat/index.html), we identified 23 out of the 175 genes whose level of expression had a prognostic value in the two independent cohorts. This approach allowed the selection of DNA repair genes that could provide a selective advantage to CN-AML cells through adaptation to replicative stress and chemoresistance. Among them, a high expression of 19 genes was associated with a poor outcome (Table 1). No statistically significant prognostic value was found for any gene involved in the NHEJ pathway.

Table 1. List of the 23 probe sets associated with good or bad prognosis in cytogenetically normal acute myeloid leukemias (CN-AML). Corresponding DNA repair pathway, gene symbol, adjusted p-value, hazard ratio, and prognosis significance are provided for each gene.

\begin{tabular}{|c|c|c|c|c|c|}
\hline $\begin{array}{l}\text { DNA Repair } \\
\text { Pathway }\end{array}$ & Probe Set & $\begin{array}{l}\text { Gene } \\
\text { Symbol }\end{array}$ & $\begin{array}{l}\text { Benjamini-Hochberg } \\
\text { Corrected } p \text {-Value }\end{array}$ & Hazard Ratio & Prognosis \\
\hline \multirow{4}{*}{$\begin{array}{l}\text { Base Excision } \\
\text { Repair pathway } \\
\text { (BER) }\end{array}$} & 210027_s_at & APEX1 & 0.02 & 1.6 & $\mathrm{Bad}$ \\
\hline & 209731_at & NTHL1 & 0.0016 & 1.9 & Bad \\
\hline & 202330_s_at & UNG & 0.0095 & 2 & Bad \\
\hline & 203655_at & XRCC1 & 0.022 & 1.6 & Bad \\
\hline \multirow{6}{*}{$\begin{array}{l}\text { Fanconi } \\
\text { pathway } \\
\text { (FANC) }\end{array}$} & 209902_at & ATR & 0.0048 & 1.8 & Bad \\
\hline & 214727 at & BRCA2 & 0.0049 & 0.58 & Good \\
\hline & 203719 at & ERCC1 & 0.0037 & $\begin{array}{l}.00 \\
1.9\end{array}$ & Bad \\
\hline & 203678_at & FAN1 & 0.0028 & 1.8 & Bad \\
\hline & 221206_at & PMS2 /// & 0.024 & 1.8 & Bad \\
\hline & 219317_at & $\begin{array}{l}\text { PMS2CL } \\
\text { POLI }\end{array}$ & 0.0016 & 1.9 & $\mathrm{Bad}$ \\
\hline \multirow{6}{*}{$\begin{array}{l}\text { Homologous } \\
\text { Recombination } \\
\text { Repair } \\
\text { pathway } \\
\text { (HRR) }\end{array}$} & 214727_at & BRCA2 & 0.0049 & 0.58 & Good \\
\hline & 205395_s_at & MRE11A & 0.015 & 1.8 & Bad \\
\hline & 205647_at & RAD52 & 0.044 & 1.9 & Bad \\
\hline & 206092_x_at & RTEL1 & 0.00047 & 2.5 & Bad \\
\hline & 212275_s_at & SRCAP & 0.014 & 0.6 & Good \\
\hline & 207598_x_at & XRCC2 & 0.007 & 1.7 & Bad \\
\hline \multirow{3}{*}{$\begin{array}{c}\text { Mismatch Repair } \\
\text { pathway } \\
\text { (MMR) }\end{array}$} & 205887_x_at & MSH3 & 0.000043 & 2.8 & Bad \\
\hline & 221206_at & PMS2 //I & 0.024 & 1.8 & Bad \\
\hline & 1053_at & RFC2 & 0.023 & 1.6 & Bad \\
\hline \multirow{8}{*}{$\begin{array}{l}\text { Nucleotide } \\
\text { Excision } \\
\text { Repair } \\
\text { pathway } \\
\text { (NER) }\end{array}$} & 201405_s_at & COPS6 & 0.011 & 1.7 & Bad \\
\hline & 213579_s_at & EP300 & 0.019 & 0.59 & Good \\
\hline & 203719_at & ERCC1 & 0.0037 & 1.9 & Bad \\
\hline & 205162_at & ERCC8 & 0.04 & 1.5 & $\mathrm{Bad}$ \\
\hline & 223758_s_at & GTF2H2 & 0.033 & 1.5 & $\mathrm{Bad}$ \\
\hline & 201046_s_at & RAD23A & 0.0067 & 0.53 & Good \\
\hline & 205672_at & XPA & 0.0035 & 1.8 & Bad \\
\hline & 203655_at & XRCC1 & 0.022 & 1.6 & Bad \\
\hline
\end{tabular}

To further corroborate gene expression data on a functional level, we studied CRISPR or RNAi screening publicly available data (Dependency Map data, Broad Institute, www.depmap.org) [30,31]. Interestingly, among the 19 genes associated with a poor outcome, APEX1 (BER), RTEL1 (HRR), and COPS6 (NER) were identified as significant essential AML genes $\left(p=7.9 \times 10^{-5}, 3.4 \times 10^{-4}\right.$, and $2.8 \times 10^{-4}$ respectively) (Figure 1 ). 
APEX1
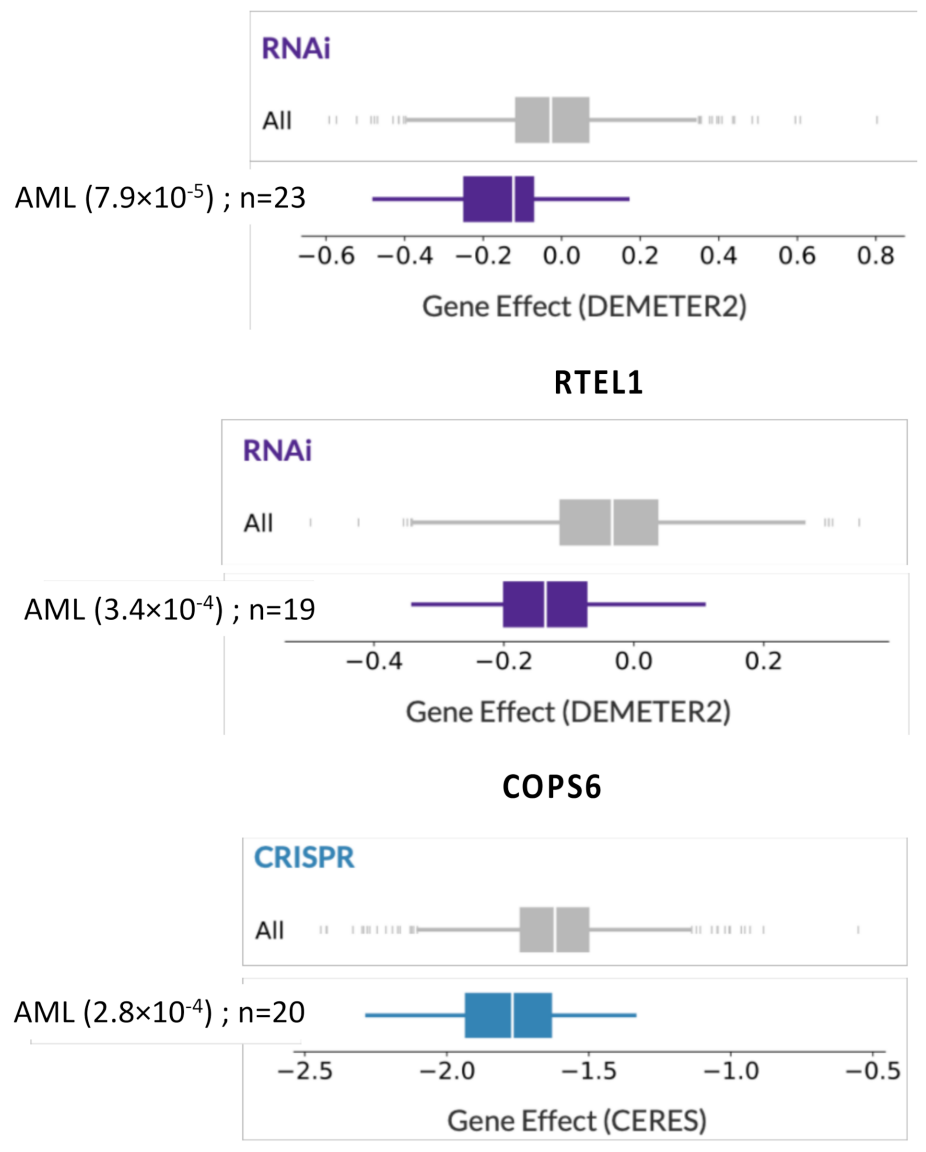

Figure 1. The silencing of APEX1, RTEL1, and COPS6 impairs acute myeloid leukemia (AML) cell growth. Using CRISPR or RNAi screening publicly available data (Dependency Map data, Broad Institute, www.depmap.org), dependency scores of APEX1, RTEL1, and COPS6 underline their specific importance for AML cell survival compared to all cell lines tested.

\subsection{GEP-Based DNA Repair Score for Predicting CN-AML Patients' Survival}

Then, we searched to combine the prognostic information of these genes in a GE-based DNA repair risk score. The 23 DNA repair genes associated with a prognostic value included 4 coding genes for the BER pathway, 6 genes for the FANC pathway, 6 genes for the HRR pathway, 3 genes for the MMR pathway, and 8 genes for the NER pathway (Table 1). Four out of these 23 probe sets (BRCA2, ERCC1, PMS2/PMS2CL, and XRCC1) were involved in two different pathways. A specific GE-based risk score was established for BER, FANC, HRR, MMR, and NER DNA repair pathways. GE-based DNA repair scores were defined by the sum of the beta coefficients of the Cox model for each prognostic gene, weighted by +1 or -1 according to the patient signal above or below/equal the probe set MaxStat value as previously described [32-35]. Using the Maxstat $\mathrm{R}$ function, high BER, FANC, HRR, MMR, and NER score values were significantly associated with poor prognosis in the training cohort (Supplementary Figure S1).

In Cox multivariate analysis, only HRR and NER scores remained associated with overall survival in the training cohort (Table 2). Therefore, a global DNA repair score was established, incorporating the prognostic value of HRR and NER scores. To this aim, CN-AML patients were split into three subgroups: group I included patients with low NER and HRR risk score values $(n=20)$, group III included patients with high NER and HRR risk scores $(n=87)$, and group II included patients with NER or HRR high-risk score value $(n=55)$. 
Table 2. Cox analysis of overall survival in CN-AML training cohort $(n=162)$ according to DNA repair pathway scores. Hazard ratio (HR) and p-values are shown for each DNA repair pathway score in univariate and multivariate Cox analysis. NS: not significant.

\begin{tabular}{clccc}
\hline \multirow{2}{*}{$\begin{array}{c}\text { DNA Repair } \\
\text { Pathway Score }\end{array}$} & \multicolumn{2}{c}{ Univariate Cox Analysis } & \multicolumn{2}{c}{ Multivariate Cox Analysis } \\
\cline { 2 - 5 } & HR & $\boldsymbol{p}$-Value & HR & $\boldsymbol{p}$-Value \\
\hline BER score & 1.97 & $1.44 \times 10^{-3}$ & 0.93 & $\mathrm{NS}$ \\
FANC score & 2.32 & $2.98 \times 10^{-5}$ & 1.30 & $\mathrm{NS}$ \\
HRR score & 3.23 & $2.16 \times 10^{-7}$ & 2.36 & $5.89 \times 10^{-4}$ \\
MMR score & 2.80 & $1.59 \times 10^{-4}$ & 1.58 & $\mathrm{NS}$ \\
NER score & 3.83 & $2.90 \times 10^{-4}$ & 2.54 & $1.66 \times 10^{-2}$ \\
\hline
\end{tabular}

After a median follow-up of 1176 days (95\% CI: 916-NR), the median overall survival (OS) was 293 days (95\% CI: 252-461) for the whole training cohort (Figure S2a). One-year OS was $45.2 \%$ (95\% CI: 38.0-53.8). According to risk groups determined by the DNA repair score, median OS was not reached (95\% CI: NR-NR), 693 days (95\% CI: 414-NR) and 233 days (95\% CI: 184-260) respectively for patients in groups I, II, and III (Figure 2a). Median OS were statistically different between each risk group (log-rank test; $p=0.016$ between group I and II; $p<0.001$ between group II and III).

We searched to validate these results in an independent cohort of 78 patients. HRR and NER scores computed with training cohort parameters were also prognostic in this validation cohort (Table S2). The global DNA repair score was also computed. In the validation set, risk groups included 14, 42, and 22 patients respectively in groups I, II, and III. After a median follow-up of 1183 days ( $95 \%$ CI: 1092-1383), the median overall survival (OS) was 538 days (95\% CI: 388-1278) for the whole validation cohort (Figure S2b). One-year OS was 61.1\% (95\% CI: 51.1-73.0). According to risk groups determined by the DNA repair score, median OS was not reached (95\% CI: 538-NR), 787 days (95\% CI: 473-NR) and 120 days (95\% CI: 36-303), respectively for patients in groups I, II, and III (Figure 2b). Even if survival analysis failed to demonstrate a statistical difference between groups I and II (log-rank test; $p=0.287$ ), OS was still statistically different between risk groups II and III (log-rank test; $p<0.001$ ).

We also validated the prognostic value of the DNA repair score in another independent cohort (Verhaak cohort) with CN-AML [36-38] using the same parameters defined within the training cohort. Of major interest, the DNA repair score was also a significant prognostic factor in this cohort of 181 patients $(p=0.03)$ for overall survival (Figures S2c and S3a). Furthermore, the DNA repair score was also a poor prognostic factor for event-free survival (EFS) (Figure S3b) suggesting an association of DNA repair score with disease relapse (events were defined as progressive disease, relapse, or death).

There was no significant difference between subgroups according to age in these three cohorts (Figure S4). Altogether, these data underlined the identification of high-risk CN-AML patients characterized by DNA repair dysregulation and that might benefit from DNA repair targeted therapies. 
(a)

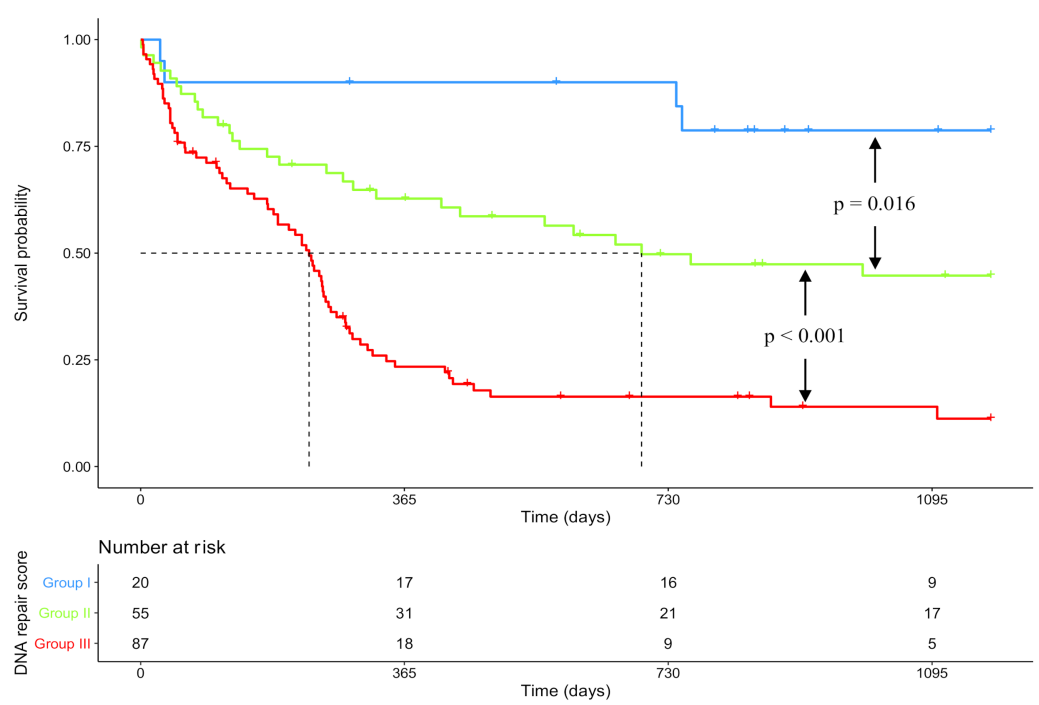

(b)
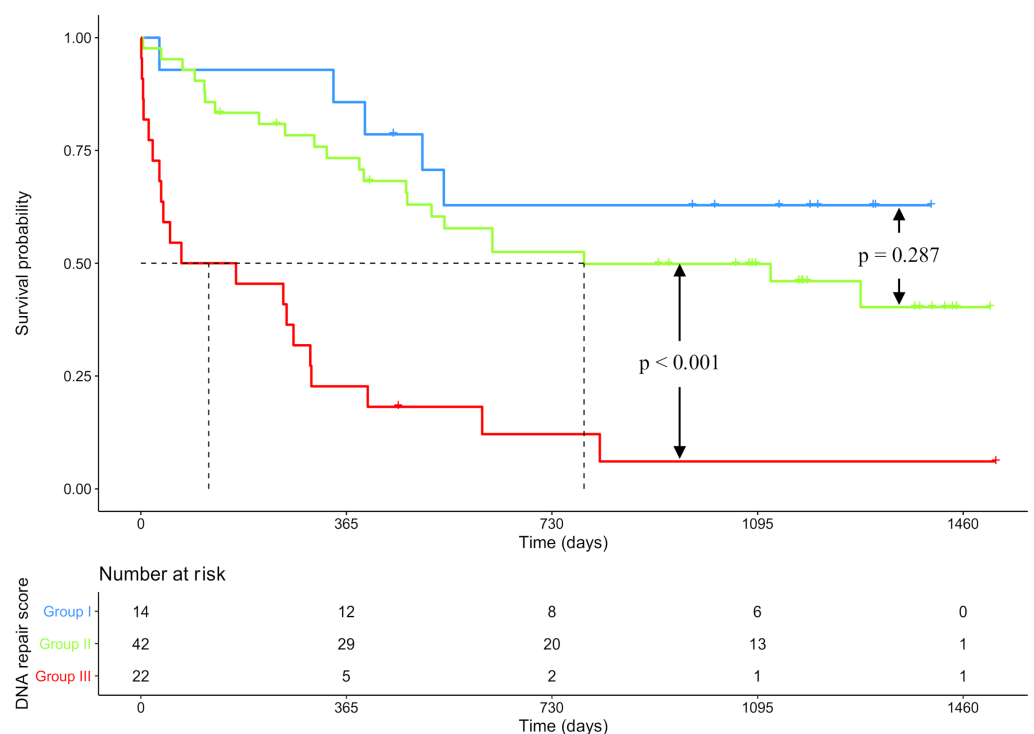

Figure 2. Kaplan-Meier survival curves according to risk stratification determined by DNA repair score. (a) Kaplan-Meier survival curve in the training cohort $(n=162)$. Median OS was not reached (95\% CI: NR-NR), 693 days (95\% CI: 414-NR) and 233 days (95\% CI: 184-260) respectively for patients in groups I (low DNA repair score), II (medium DNA repair score) and III (high DNA repair score). One-year OS was $90.0 \%$ (95\% CI: 77.7-100) in group I, 62.8\% (95\% CI: 51.1-77.2) in group II, and 23.4\% (95\% CI: 15.8-34.7) in group III. (b) Kaplan-Meier survival curve in the validation cohort $(n=78)$. Median OS was not reached (95\% CI: 538-NR), 787 days (95\% CI: 473-NR) and 120 days (95\% CI: 36-303) respectively for patients in groups I (low DNA repair score), II (medium DNA repair score) and III (high DNA repair score). One-year OS was 85.7\% (95\% CI: 69.2-100) in group I, 73.3\% (95\% CI: 60.9-88.2) in group II, and $22.7 \%$ (95\% CI: 10.5-49.1) in group III. $p$-values were determined with the log-rank test. NR: not reached.

2.3. DNA Repair Score and NPM1 / FLT3 Mutational Status Combination as Prognosis Factors in CN-AML

Because NPM1 mutations and FLT3-ITD (internal tandem duplication) are well-described prognosis factors in CN-AML, we conducted another Cox analysis to determine whether our DNA repair score provides additional prognostic information. Prognostic classification according to NPM1 and FLT3 mutational status was established in both cohort according to actual recommendations [3]: patients with only NPM1 mutation were classified as "better outcome", patients with only FLT3-ITD were 
classified as "adverse prognosis" and patients with both or none of these mutations were classified as "intermediate prognosis". Kaplan-Meier survival curves according to NPM1 and FLT3 mutational status are presented in Supplementary Figure S5 for both training and validation cohorts.

Using multivariate Cox analysis, our DNA repair score and NPM1/FLT3 mutation classification remained independently associated with survival (Table 3 and Table S3). Therefore, we investigated the interest of combining DNA repair score and NPM1 / FLT3 mutational status to predict CN-AML outcome. Patients were classified according to prognosis value of DNA repair score (0 point for group I; 1 for group II; 2 for group III), and NPM1 / FLT3 mutational status (0 point if NPM1 mutated without FLT3-ITD; 2 points if FLT3-ITD without NPM1 mutation; 1 point in other situations). The sum of the prognostic information was computed for all patients, splitting the training cohort in five groups. When the Kaplan-Meier analysis did not show a significant OS difference between consecutive groups, we merged the two groups. This approach resulted in three prognostic groups with significant different OS values: group $A$ for patients with 0 or 1 point, group $B$ for patients with 2 points, and group $C$ for patients with 3 or 4 points. (Table 4 and Figure S6).

Table 3. Cox analysis of overall survival in CN-AML training cohort $(n=162)$ according to DNA repair score, and NPM1/FLT3 mutational status. Hazard ratio (HR) and p-values are shown for each parameter in univariate and multivariate Cox analysis. ITD: internal tandem duplication.

\begin{tabular}{ccccc}
\hline \multirow{2}{*}{ Scores } & \multicolumn{2}{c}{ Univariate Cox Analysis } & \multicolumn{2}{c}{ Multivariate Cox Analysis } \\
\cline { 2 - 5 } & HR & $p$-Value & HR & $p$-Value \\
\hline DNA repair score & 2.76 & $1.49 \times 10^{-8}$ & 2.66 & $5.1 \times 10^{-8}$ \\
NPM1 mutation/FLT3-ITD classification & 1.81 & $1.18 \times 10^{-4}$ & 1.76 & $6.2 \times 10^{-4}$ \\
\hline
\end{tabular}

Table 4. DNA repair score and NPM1/FLT3 mutational status combination to establish a global prognosis score in CN-AML. Patients were classified according to DNA repair score risk group (I, II or III) and NPM1/FLT3 mutational status.

\begin{tabular}{|c|c|c|c|c|}
\hline & & \multicolumn{3}{|c|}{ Classification According to DNA Repair Score } \\
\hline & & $\begin{array}{l}\text { Group I } \\
0 \text { point }\end{array}$ & $\begin{array}{l}\text { Group II } \\
1 \text { point }\end{array}$ & $\begin{array}{l}\text { Group III } \\
2 \text { points }\end{array}$ \\
\hline \multirow{3}{*}{$\begin{array}{l}\text { NPM1 and FLT3 } \\
\text { mutational status }\end{array}$} & $\begin{array}{c}\text { NPM1+ and FLT3-ITD- } \\
0 \text { point }\end{array}$ & 0 & 1 & 2 \\
\hline & $\begin{array}{c}\text { NPM1+ and FLT3-ITD+ } \\
\text { or } \\
\text { NPM1- and FLT3-ITD- } \\
1 \text { point }\end{array}$ & 1 & 2 & 3 \\
\hline & $\begin{array}{l}\text { NPM1- and FLT3-ITD+ } \\
2 \text { points }\end{array}$ & 2 & 3 & 4 \\
\hline
\end{tabular}

Patients with NPM1 mutation or FLT3-ITD are respectively designated by NPM1+ and FLT3-ITD+. Patients without NPM1 mutation or FLT3-ITD are respectively designated by NPM1- and FLT3-ITD-. Points were attributed as described in the table. Patients with 0 or 1 point were grouped in group A (green), patients with 2 points were grouped in group B (yellow), and patients with 3 or 4 points were grouped in group C (red). ITD: internal tandem duplication.

In the training cohort, median OS was not reached (95\% CI: NR-NR), 326 days (95\% CI: 127-NR) and 236 days (95\% CI: 190-263) respectively for patients in groups A, B, and C. One-year OS was $90.3 \%$ (95\% CI: 80.5-100) in group A, $49.3 \%$ (95\% CI: 37.1-65.7) in group B and $24.2 \%$ (95\% CI: $16.2-36.2)$ in group $\mathrm{C}$. These results were confirmed in the validation cohort where median OS was not reached (95\% CI: 1278-NR), 516 days (95\% CI: 308-NR) and 253 days (95\% CI: 52-403) for patients respectively in groups A, B, and C. One-year OS was $92.6 \%$ (95\% CI: 83.2-100) in group A, 54.9\% (95\% CI: 39.8-75.7) in group B and $26.5 \%$ (95\% CI: 12.4-55.8) in group C. OS was statistically different between groups A, B, and $C$ in both training and validation cohorts (Figure 3). Altogether, these data underlined the interest of GEP-based DNA repair deregulations, alone or in combination with NPM1 and FLT3 mutational status to identify high-risk CN-AML patients. 
(a)
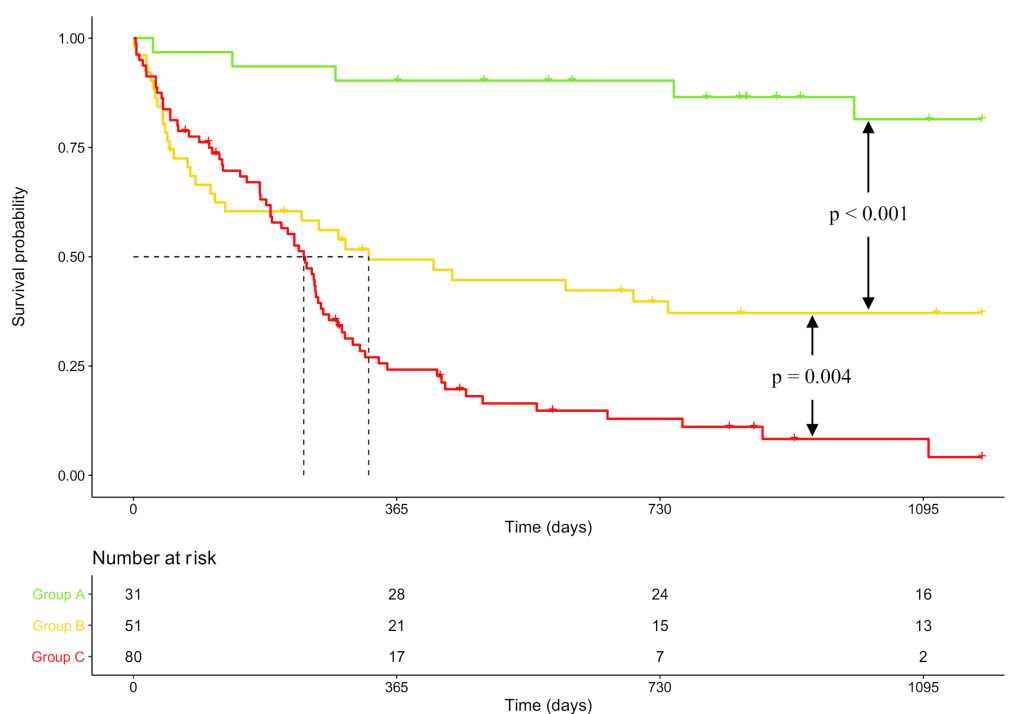

(b)

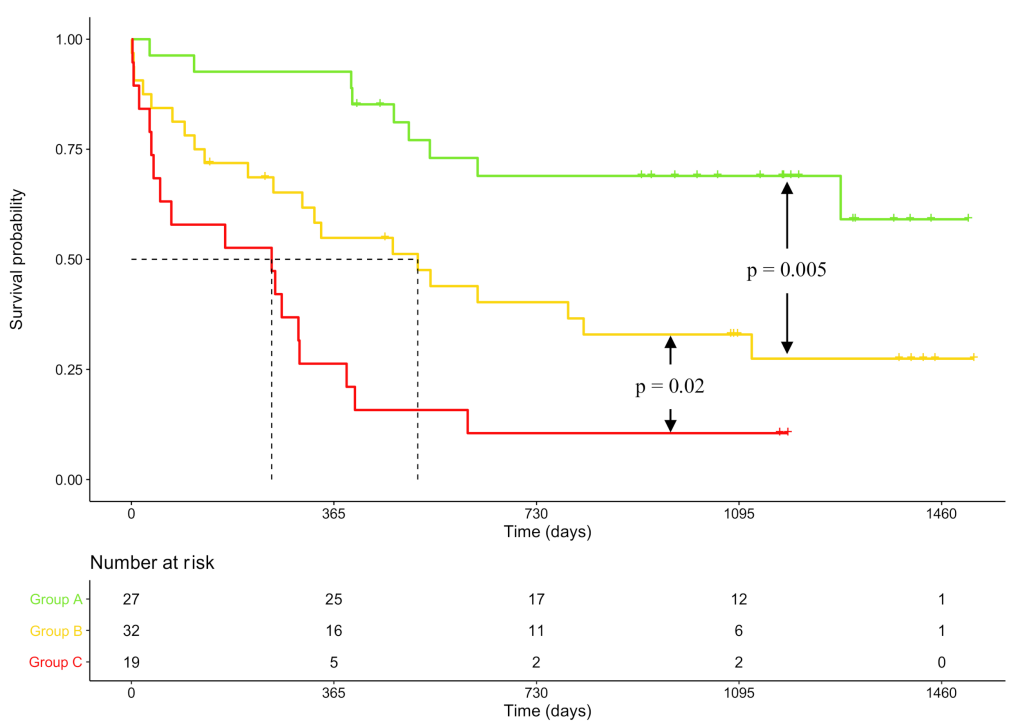

Figure 3. Kaplan-Meier survival curves according to risk groups determined by combined score incorporating DNA repair score and NPM1/FLT3 mutational status. (a) Kaplan-Meier survival curve in the training cohort $(n=162)$. Median OS was not reached (95\% CI: NR-NR), 326 days (95\% CI: $127-N R)$ and 236 days (95\% CI: 190-263) respectively for patients in groups A, B and C. One-year OS was $90.3 \%$ (95\% CI: 80.5-100) in group A, 49.3\% (95\% CI: 37.1-65.7) in group B, and 24.2\% (95\% CI: 16.2-36.2) in group C. (b) Kaplan-Meier survival curve in the validation cohort $(n=78)$. Median OS was not reached (95\% CI: 1278-NR), 516 days (95\% CI: 308-NR) and 253 days (95\% CI: $52-403$ ) respectively for patients in groups A, B and C. One-year OS was $92.6 \%$ (95\% CI: 83.2-100) in group A, 54.9\% (95\% CI: $39.8-75.7)$ in group B, and $26.5 \%$ (95\% CI: $12.4-55.8)$ in group C. $p$-values were determined with the log-rank test. NR: not reached.

\section{Discussion}

Despite an improvement in prognosis classification, mostly based on the identification of gene mutations such as NPM1, FLT3, or CEBPA, outcomes in CN-AML remain heterogeneous, underlying the wide diversity of this AML subset. In this study, we developed a GE-based score using data from genes involved in the DNA damage response. Our model succeeded to predict poor outcomes in three independent cohorts of adult patients with CN-AML treated with intensive chemotherapy. Combining DNA repair score with NPM1 and FLT3-ITD mutational status allows us to distinguish three prognostic 
groups including a low-risk group with a not reached median OS after a median follow-up of more than 3 years in both cohorts, a high-risk group with a median OS of about 8 months in both cohorts, and an intermediate risk-group. Furthermore, the DNA repair score is also a prognostic factor for EFS underlining a potential role of DNA repair pathway deregulation in disease relapse. This model may therefore be used for risk stratification in CN-AML since DNA repair scores could be calculated for new patients using Affymetrix microarray data if the same methodology of normalization is applied. Prospective validation of DNA repair score prognostic value using RNA-seq data will be of interest in future investigations.

Among the GEP-based defined DNA-repair scores built into our study, HRR and NER scores remained independent prognostic factors in CN-AML. HRR pathway is a process involved in DNA double-strand break (DSB) repair, in which complementary sister chromatid is used as a template for an error-free repair of DNA sequence [39,40]. Among the prognostic factors composing the DNA repair score, MRE11A is a nuclease involved in the MRN complex (for MRE11, RAD50 and NBS1) which acts as a sensor for DSB damage [41,42]. RAD52, BRCA2, XRCC2 are proteins directly involved in the DNA repair process [40,43], and RTEL1 and SRCAP are regulators of HRR [44,45]. NER pathway is involved in the recognition and repair of lesions that disrupt DNA double helices, such as adducts or inter-strand crosslinks (ICL) $[46,47]$. RAD23A and COPS6 are involved in DNA damage recognition. The recruitment of the DNA incision complex, in which ERCC1, ERCC8, and GTF2H2 are involved, is mediated by XPA $[46,48]$. XRCC1 and EP300 are respectively involved in DNA final ligation process and NER regulation $[49,50]$. Several polymorphisms in genes involved in HRR and NER have been correlated with AML onset and outcome. RAD51 is a key protein in the HRR pathway. Its polymorphic variant RAD51-G135C has been suggested to be correlated with the onset of therapy-related AML by several case-control studies, even if two meta-analyses seem to dismiss the role of this polymorphism in de novo AML onset [51-54]. XPD is involved in the NER pathway, and its polymorphism XPD-Lys751Gln has been shown to be a risk factor for AML onset [10,51,52]. One study also suggested that this polymorphism worsens the AML prognosis [55]. These data highlight the role of DNA repair pathways in leukemogenesis and suggest their role in chemotherapy resistance.

Interestingly, when compared using multivariate analysis, the DNA repair score and NPM1/FLT3 mutational status remained statistically associated with the outcome in CN-AML. The poor prognosis of FLT3-ITD mutated CN-AML has been demonstrated for a high ITD-to-wild-type allelic ratio (>0.5) [56]. Unfortunately, this ratio was not available in these cohorts, and we approximated that all patients with FLT3-ITD would have a worse prognosis compared to the others. Moreover, other prognostic mutations defined in ELN 2017 classification (CEBPA, TP53, RUNX1, ASXL1, and biallelic mutation of CEBPA) were not available. A combination of DNA repair scores with the mutational status for these genes may provide a more precise risk classification of patients according to recommendations. Studying the correlation between our DNA repair score and others frequently mutated genes in AML may also be of interest, especially for genes involved in chromatin organization and stability (DNMT3A, IDH1/2, TET2, KMT2A, EZH2). Therefore, it will be compelling to investigate the link between FLT3-ITD allelic ratio, recurrent $\mathrm{CN}$-AML mutations, and the described GEP-based DNA-repair risk score in a new prospective cohort.

Intensive chemotherapy for CN-AML patients usually includes cytarabine and anthracyclines (daunorubicine or idarubicine) [57]. Cytarabine, a nucleoside analog, incorporates into DNA and interferes with DNA synthesis during the phase $S$ of the cell cycle, leading to genomic instability [58]. Anthracyclines are DNA topoisomerase II inhibitors that induce DNA damages such as DSB, adducts, and ICL [58]. Therefore, overexpression of HRR or NER pathway genes could be associated with chemotherapy resistance, but a better understanding of the functional role of DNA repair pathways in the pathogenesis and drug resistance of CN-AML is needed [59]. Gene silencing approaches by sh-RNA or CRISPR-Cas9 strategies could be of particular interest. Thus, CRISPR-Cas9 or RNAi screening revealed that APEX1 (BER), RTEL1 (HRR), and COPS6 (NER) are essential AML genes. Among these genes, COPS6 overexpression is associated with poor outcomes in many solid tumors. Interestingly, 
COPS6 depletion showed in vivo efficacy against glioblastoma [60], cervical cancer [61], or papillary thyroid carcinoma [62], through the regulation of several signaling pathways. However, the biological function of COPS6 in leukemogenesis and AML drug-resistance remains largely unknown.

Therefore, inhibiting DNA repair might be a promising strategy to improve the efficacy of genotoxic drugs and overcome drug resistance, according to the principle of "synthetic lethality" $[63,64]$. Poly-(ADP Ribose) Polymerase (PARP) inhibitors (talazoparib, olaparib) has been recently approved for the treatment of breast and ovarian cancers with BRCA1/2 mutations, and several others drugs inhibiting or modulating DNA repair pathways are currently in clinical development for cancer therapy (Table 5). In preclinical studies, APEX1 inhibitor has demonstrated promising toxicity on primary AML cells in vitro, alone or in association with hypomethylating agent decitabine or with PARP inhibitor talazoparib. Even if APEX1 expression levels did not significantly differ between responding and non-responding AML cells, APEX1 inhibitor appeared promising in normal karyotype AML ( $83 \%$ of the patients with response to APEX1 inhibitor) [65]. Moreover, several other compounds targeting proteins involved in DNA repair mechanisms have already shown promising results as potential new anti-cancer drugs in pre-clinical studies, such as BLM [66], WRN [67], RAD52 [68], or MRE11 [69] inhibitors.

Table 5. A non-exhaustive list of recruiting clinical trials for DNA repair targeting drugs in 2020 (www.clinicaltrials.gov). ADK: adenocarcinoma. AML: acute myeloid leukemia. ASCT: autologous stem cell transplant. GO: gemtuzumab ozogamicin. MDS: myelodysplastic syndrome. R/R: relapsed or refractory. SQCLC: squamous cell lung carcinoma.

\begin{tabular}{|c|c|c|c|c|c|}
\hline Target & Drug & Cancer & Phase & Intervention & Identifier \\
\hline \multicolumn{6}{|c|}{ Base Excision Repair (BER) Pathway } \\
\hline APEX1 & TRC -102 & $\begin{array}{l}\text { Solid tumors \& } \\
\text { lymphomas }\end{array}$ & $\mathrm{I} / \mathrm{II}$ & TRC-102 + temozolomide & NCT01851369 \\
\hline \multirow{6}{*}{ PARP1/2 } & Niraparib & Pancreatic ADK & II & Niraparib alone & NCT03601923 \\
\hline & Olaparib & $\begin{array}{l}\text { Lymphomas } \\
\text { (B/T/Hodgkin) }\end{array}$ & I & $\begin{array}{l}\text { Olaparib + high-dose } \\
\text { chemotherapy + ASCT }\end{array}$ & NCT03259503 \\
\hline & Olaparib & $\begin{array}{l}\text { AML or MDS with } I D H 1 / 2 \\
\text { mutation }\end{array}$ & II & Olaparib alone & NCT03953898 \\
\hline & Talazoparib & R/R AML CD33+ & $\mathrm{I} / \mathrm{II}$ & Talazoparib + GO & NCT04207190 \\
\hline & Talazoparib & AML & $\mathrm{I} / \mathrm{II}$ & Talazoparib + Decitabine & NCT02878785 \\
\hline & Veliparib & $\begin{array}{l}\text { Myeloproliferative } \\
\text { disorders }\end{array}$ & II & $\begin{array}{c}\text { Carboplatin + Topotecan +/- } \\
\text { Veliparib }\end{array}$ & NCT03289910 \\
\hline \multicolumn{6}{|c|}{ Homologous Recombination Repair (HRR) Pathway } \\
\hline ATM & AZD1390 & Glioblastoma & I & AZD1390 + radiotherapy & NCT03423628 \\
\hline CHEK-1/2 & Prexasertib & $\mathrm{R} / \mathrm{R}$ medulloblastoma & I & $\begin{array}{c}\text { Prexasertib + Gemcitabine or } \\
\text { Cyclophosphamide }\end{array}$ & NCT04023669 \\
\hline RAD51 & CYT-0851 & $\begin{array}{l}\text { Solid tumors \& B-cell } \\
\text { lymphomas }\end{array}$ & $\mathrm{I} / \mathrm{II}$ & CYT-0851 alone & NCT03997968 \\
\hline \multicolumn{6}{|c|}{ Fanconi (FANC) Pathway } \\
\hline ATM & & & see abov & & \\
\hline \multirow{2}{*}{ ATR } & Ceralasertib & $\begin{array}{l}\text { R/R non-Hodgkin's } \\
\text { lymphoma }\end{array}$ & I & Ceralasertib + Acalabrutinib & NCT03527147 \\
\hline & M6620 & Solid tumors & II & MS6620 alone & NCT03718091 \\
\hline RAD51 & \multicolumn{5}{|c|}{ (see above) } \\
\hline \multicolumn{6}{|c|}{ Nucleotide Excision Repair (NER) pathway } \\
\hline \multirow{3}{*}{ CDK7 } & LY3405105 & Solid tumors & I & LY3405105 alone & NCT03770494 \\
\hline & SY5609 & Solid tumors & I & SY5609 +/- Fulvestrant & NCT04247126 \\
\hline & CT7001 & Solid tumors & $\mathrm{I} / \mathrm{II}$ & CT7001 +/- Fulvestrant & NCT03363893 \\
\hline \multicolumn{6}{|c|}{ Others } \\
\hline WEE1 & Adavosertib & SQCLC & II & $\begin{array}{c}\text { Adavosertib + Paclitaxel + } \\
\text { Carboplatin }\end{array}$ & NCT02513563 \\
\hline $\begin{array}{l}\text { PARP1/2 + ATR } \\
\text { or WEE1 }\end{array}$ & $\begin{array}{c}\text { Olaparib } \\
\text { Ceralasertib } \\
\text { Adavosertib }\end{array}$ & $\begin{array}{l}\text { Metastatic triple negative } \\
\text { breast cancer }\end{array}$ & II & $\begin{array}{c}\text { Olaparib alone } \\
\text { or Olaparib + Ceralasertib } \\
\text { or Olaparib + Adavosertib }\end{array}$ & NCT03330847 \\
\hline
\end{tabular}


Our data support the potential of DNA repair scores to identify CN-AML patients whose malignant cells are dependent on specific DNA repair pathways to design targeted therapy with ATM, CHEK-1/2, RAD51, or CDK7 inhibitors exploiting the addiction to deregulated DNA repair mechanisms.

\section{Materials and Methods}

\subsection{Patients and Gene Expression Data}

Gene expression microarray data from two independent cohorts of adult patients diagnosed with $\mathrm{CN}-\mathrm{AML}$ were used. One patient was excluded from each cohort due to a diagnosis of myelodysplastic syndrome. Thus, the first cohort (training set) included 162 patients and the second one (validation set) 78 patients. At least 20 metaphases were analyzed for each patient to confirm the normal karyotype. At the beginning of treatment, the median age was 57.5 years in the training cohort and 62 years in the validation cohort. Pretreatment clinical characteristics of patients have been described previously [70]. At diagnosis, training and validation cohorts statistically differed according to FLT3-ITD positive patients ( $48 \%$ vs. $22 \%$, respectively) and median leucocyte count ( $36.9 \mathrm{G} / \mathrm{L}$ vs. $15.9 \mathrm{G} / \mathrm{L}$, respectively). NPM1 and FLT3 mutational status were kindly provided for each patient by Metzeler et al. [70]. FLT3-ITD allelic ratio and mutational status for other prognostic genes (CEBPA, TP53, ASXL1, RUNX1) were not available in these cohorts. All patients were treated with intensive chemotherapy. Another cohort (Verhaak cohort) comprising 181 patients with de novo CN-AML was used for validation. The median age at diagnosis was 46 years in this cohort All the patient's characteristics have been previously reported [36-38].

Affymetrix gene expression data are publicly available via the online Gene Expression Omnibus (http://www.ncbi.nlm.nih.gov/geo/) under accession number GSE12417 and GSE14468. They were performed using Affymetrix HG-U133 A\&B arrays for training cohort and Affymetrix HG-U133 Plus 2.0 arrays for the validation and Verhaak sets. Normalization of microarray data was performed using the variance stabilizing normalization algorithm, and probe set signals calculated by the median polish method [36-38,70,71]. Quality control consisted of visual inspection of the array image for artifacts, assessment of RNA degradation plots, and inspection of rank-vs-residual plots after normalization and probe set summarization.

\subsection{Selection of Prognostic Genes}

DNA repair gene list was defined using the REPAIRtoire database (http://repairtoire.genesilico.pl) and review of the literature (Table S1) [33]. To establish gene expression (GE)-based risk scores, we selected probe sets whose expression values were significantly associated with overall survival using MaxStat $\mathrm{R}$ function, which allows us to determine the optimal cutpoint for continuous variables, and Benjamini-Hochberg multiple testing correction in two independent cohorts (adjusted $p$-value $<0.05)$.

\subsection{Building DNA Repair Gene Expression-Based Risk Score}

For each pathway, a GE-based risk score was created as the sum of the beta coefficients weighted by +1 or -1 according to the patient signal above or below/equal the probe set MaxStat value as previously reported [32-35]. Patients from the training cohort were ranked according to increased prognostic score and for a given score value $X$, the difference in survival of patients with a prognostic score $\leq \mathrm{X}$ or $>\mathrm{X}$ was computed using MaxStat analysis.

Cox proportional hazards model was performed to determine statistically significant pathway scores in multivariate analysis. A global DNA repair score was calculated based on the pathway scores which remained statistically significant in this analysis. Survival analyses were assessed using the Kaplan-Meier method, and survival curves were compared using the log-rank test. 


\subsection{Validation of the DNA Repair Score on Validation Cohort}

Pathway and DNA repair scores were individually calculated in both validation and Verhaak cohort, using the cutoff values determined for the training cohort. Survival analyses were assessed using Kaplan-Meier method, and survival curves were compared using the log-rank test.

\subsection{Statistical Analyses}

All statistical tests were two-tails and Alpha-risk was fixed at 5\%. Analyses were performed using R.3.6.0. (R Foundation for Statistical Computing, Vienna, Austria) and SPSS Statistics version 23.0.0.0 for Mac (SPSS Inc., Chicago, IL, USA).

\section{Conclusions}

The DNA repair score may be useful to identify high-risk CN-AML patients and define the best DNA repair inhibitor to use in combination with conventional treatment to improve patients' outcomes. The DNA repair score could also be valuable for adapting targeted treatment according to the drug resistance mechanisms selected during the clonal evolution of relapsing AML. These advances may improve the survival of CN-AML patients, and limit the side effects of treatment, improving compliance with dosing regimens and overall quality of life.

Supplementary Materials: The following are available online at http://www.mdpi.com/2072-6694/12/10/2874/s1, Figure S1: Prognostic value of DNA repair pathway scores in CN-AML patients of the training cohort, Figure S2: Kaplan-Meier survival curves for training and validation cohorts, Figure S3: Kaplan-Meier survival curves according to risk stratification determined by DNA repair score in Verhaak cohort, Figure S4: Distribution of age (years) in each DNA repair score subgroups (I, II and III) for training and validation cohorts, Figure S5: Kaplan-Meier survival curves according to NPM1/FLT3 mutational status, Figure S6: Kaplan-Meier survival curve according to the points allotted to patients in Table 4 for the training cohort, Table S1: Genes coding for proteins involved in DNA repair, Table S2: Cox analysis of overall survival in CN-AML validation cohort according to DNA repair pathway scores, Table S3: Cox analysis of overall survival in CN-AML validation cohort according to DNA repair score, and NPM1 \& FLT3 mutational status.

Author Contributions: L.G. performed research, data analyses, and participated in the writing of the paper. G.B. and G.C. participated in the research and the writing of the paper. J.M. and C.B. supervised the research and the writing of the paper. All authors have read and agreed to the published version of the manuscript.

Funding: This work was supported by grants from INCa (Institut National du Cancer) PLBIO18-362 PIT-MM and PLBIO19 FATidique, ANR (TIE-Skip; 2017-CE15-0024-01), ANR-18-CE15-0010-01 PLASMADIFF-3D, SIRIC Montpellier Cancer (INCa_Inserm_DGOS_12553), Labex EpiGenMed and Institut Universitaire de France.

Conflicts of Interest: The authors declare no conflict of interest.

\section{References}

1. Grimwade, D.; Hills, R.K.; Moorman, A.V.; Walker, H.; Chatters, S.; Goldstone, A.H.; Wheatley, K.; Harrison, C.J.; Burnett, A.K.; on behalf of the National Cancer Research Institute Adult Leukaemia Working Group. Refinement of cytogenetic classification in acute myeloid leukemia: Determination of prognostic significance of rare recurring chromosomal abnormalities among 5876 younger adult patients treated in the United Kingdom Medical Research Council trials. Blood 2010, 116, 354-365. [CrossRef]

2. Port, M.; Böttcher, M.; Thol, F.; Ganser, A.; Schlenk, R.; Wasem, J.; Neumann, A.; Pouryamout, L. Prognostic significance of FLT3 internal tandem duplication, nucleophosmin 1, and CEBPA gene mutations for acute myeloid leukemia patients with normal karyotype and younger than 60 years: A systematic review and meta-analysis. Ann. Hematol. 2014, 93, 1279-1286. [CrossRef] [PubMed]

3. Döhner, H.; Estey, E.; Grimwade, D.; Amadori, S.; Appelbaum, F.R.; Büchner, T.; Dombret, H.; Ebert, B.L.; Fenaux, P.; Larson, R.A.; et al. Diagnosis and management of AML in adults: 2017 ELN recommendations from an international expert panel. Blood 2017, 129, 424-447. [CrossRef] [PubMed]

4. An the Cancer Genome Atlas Research Network Genomic and Epigenomic Landscapes of Adult De Novo Acute Myeloid Leukemia. N. Engl. J. Med. 2013, 368, 2059-2074. [CrossRef] [PubMed] 
5. Ibáñez, M.; Carbonell-Caballero, J.; Such, E.; García-Alonso, L.; Liquori, A.; López-Pavía, M.; Llop, M.; Alonso, C.; Barragán, E.; Gómez-Seguí, I.; et al. The modular network structure of the mutational landscape of Acute Myeloid Leukemia. PLoS ONE 2018, 13, e0202926. [CrossRef] [PubMed]

6. Grossmann, V.; Tiacci, E.; Holmes, A.B.; Kohlmann, A.; Martelli, M.P.; Kern, W.; Spanhol-Rosseto, A.; Klein, H.-U.; Dugas, M.; Schindela, S.; et al. Whole-exome sequencing identifies somatic mutations of BCOR in acute myeloid leukemia with normal karyotype. Blood 2011, 118, 6153-6163. [CrossRef] [PubMed]

7. Kandoth, C.; McLellan, M.D.; Vandin, F.; Ye, K.; Niu, B.; Lu, C.; Xie, M.; Zhang, Q.; McMichael, J.F.; Wyczalkowski, M.A.; et al. Mutational landscape and significance across 12 major cancer types. Nat. Cell Biol. 2013, 502, 333-339. [CrossRef] [PubMed]

8. Kayser, S.; Döhner, K.; Krauter, J.; Köhne, C.-H.; Horst, H.A.; Held, G.; Von Lilienfeld-Toal, M.; Wilhelm, S.; Kündgen, A.; Götze, K.; et al. The impact of therapy-related acute myeloid leukemia (AML) on outcome in 2853 adult patients with newly diagnosed AML. Blood 2011, 117, 2137-2145. [CrossRef]

9. Papaemmanuil, E.; Gerstung, M.; Bullinger, L.; Gaidzik, V.I.; Paschka, P.; Roberts, N.D.; Potter, N.E.; Heuser, M.; Thol, F.; Bolli, N.; et al. Genomic Classification and Prognosis in Acute Myeloid Leukemia. N. Engl. J. Med. 2016, 374, 2209-2221. [CrossRef]

10. Liu, D.; Wu, D.; Li, H.; Dong, M. The effect of XPD/ERCC2 Lys751Gln polymorphism on acute leukemia risk: A systematic review and meta-analysis. Gene 2014, 538, 209-216. [CrossRef]

11. Alcalay, M.; Meani, N.; Gelmetti, V.; Fantozzi, A.; Fagioli, M.; Orleth, A.; Riganelli, D.; Sebastiani, C.; Cappelli, E.; Casciari, C.; et al. Acute myeloid leukemia fusion proteins deregulate genes involved in stem cell maintenance and DNA repair. J. Clin. Investig. 2003, 112, 1751-1761. [CrossRef] [PubMed]

12. Krejci, O.; Wunderlich, M.; Geiger, H.; Chou, F.-S.; Schleimer, D.; Jansen, M.; Andreassen, P.R.; Mulloy, J.C. p53 signaling in response to increased DNA damage sensitizes AML1-ETO cells to stress-induced death. Blood 2008, 111, 2190-2199. [CrossRef] [PubMed]

13. Yeung, P.L.; Denissova, N.G.; Nasello, C.; Hakhverdyan, Z.; Chen, J.D.; Brenneman, M.A. Promyelocytic leukemia nuclear bodies support a late step in DNA double-strand break repair by homologous recombination. J. Cell. Biochem. 2011, 113, 1787-1799. [CrossRef] [PubMed]

14. Van Der Kouwe, E.; Staber, P.B. RUNX1-ETO: Attacking the Epigenome for Genomic Instable Leukemia. Int. J. Mol. Sci. 2019, 20, 350. [CrossRef]

15. Alter, B.P. Fanconi anemia and the development of leukemia. Best Pract. Res. Clin. Haematol. 2014, 27, 214-221. [CrossRef]

16. Quinn, E.; Nichols, K.E. Cancer predisposition syndromes associated with myeloid malignancy. Semin. Hematol. 2017, 54, 115-122. [CrossRef]

17. Schoch, C.; Kern, W.; Kohlmann, A.; Hiddemann, W.; Schnittger, S.; Haferlach, T. Acute myeloid leukemia with a complex aberrant karyotype is a distinct biological entity characterized by genomic imbalances and a specific gene expression profile. Genes Chromosom. Cancer 2005, 43, 227-238. [CrossRef]

18. Cavelier, C.; Didier, C.; Prade, N.; Mas, V.M.-D.; Manenti, S.; Recher, C.; Demur, C.; Ducommun, B. Constitutive Activation of the DNA Damage Signaling Pathway in Acute Myeloid Leukemia with Complex Karyotype: Potential Importance for Checkpoint Targeting Therapy. Cancer Res. 2009, 69, 8652-8661. [CrossRef]

19. Wang, P.; Ma, D.; Wang, J.; Fang, Q.; Gao, R.; Wu, W.; Cao, L.; Hu, X.; Zhao, J.; Li, Y. INPP4B-mediated DNA repair pathway confers resistance to chemotherapy in acute myeloid leukemia. Tumor Biol. 2016, 37, 12513-12523. [CrossRef]

20. Sallmyr, A.; Fan, J.; Datta, K.; Kim, K.-T.; Grosu, D.; Shapiro, P.; Small, D.; Rassool, F. Internal tandem duplication of FLT3 (FLT3/ITD) induces increased ROS production, DNA damage, and misrepair: Implications for poor prognosis in AML. Blood 2008, 111, 3173-3182. [CrossRef]

21. Seedhouse, C.; Hunter, H.M.; Lloyd-Lewis, B.; Massip, A.-M.; Pallis, M.; I Carter, G.; Grundy, M.; Shang, S.; Russell, N.H. DNA repair contributes to the drug-resistant phenotype of primary acute myeloid leukaemia cells with FLT3 internal tandem duplications and is reversed by the FLT3 inhibitor PKC412. Leukemia 2006, 20, 2130-2136. [CrossRef] [PubMed]

22. Aalbers, A.M.; Calado, R.T.; Young, N.S.; Zwaan, C.M.; Wu, C.; Kajigaya, S.; Coenen, E.A.; Baruchel, A.; Geleijns, K.; De Haas, V.; et al. Telomere length and telomerase complex mutations in pediatric acute myeloid leukemia. Leukemia 2013, 27, 1786-1789. [CrossRef] [PubMed] 
23. Bagrintseva, K.; Geisenhof, S.; Kern, R.; Eichenlaub, S.; Reindl, C.; Ellwart, J.W.; Hiddemann, W.; Spiekermann, K. FLT3-ITD-TKD dual mutants associated with AML confer resistance to FLT3 PTK inhibitors and cytotoxic agents by overexpression of Bcl-x(L). Blood 2005, 105, 3679-3685. [CrossRef]

24. Alpermann, T.; Schnittger, S.; Eder, C.; Dicker, F.; Meggendorfer, M.; Kern, W.; Schmid, C.; Aul, C.; Staib, P.; Wendtner, C.-M.; et al. Molecular subtypes of NPM1 mutations have different clinical profiles, specific patterns of accompanying molecular mutations and varying outcomes in intermediate risk acute myeloid leukemia. Haematologica 2015, 101, e55-e58. [CrossRef] [PubMed]

25. Okuda, M.; Horn, H.F.; Tarapore, P.; Tokuyama, Y.; Smulian, A.; Chan, P.-K.; Knudsen, E.S.; A Hofmann, I.; Snyder, J.D.; E Bove, K.; et al. Nucleophosmin/B23 Is a Target of CDK2/Cyclin E in Centrosome Duplication. Cell 2000, 103, 127-140. [CrossRef]

26. Koike, A.; Nishikawa, H.; Wu, W.; Okada, Y.; Venkitaraman, A.R.; Ohta, T. Recruitment of Phosphorylated NPM1 to Sites of DNA Damage through RNF8-Dependent Ubiquitin Conjugates. Cancer Res. 2010, 70, 6746-6756. [CrossRef]

27. Lirussi, L.; Antoniali, G.; Vascotto, C.; D’Ambrosio, C.; Poletto, M.; Romanello, M.; Marasco, D.; Leone, M.; Quadrifoglio, F.; Bhakat, K.K.; et al. Nucleolar accumulation of APE1 depends on charged lysine residues that undergo acetylation upon genotoxic stress and modulate its BER activity in cells. Mol. Biol. Cell 2012, 23, 4079-4096. [CrossRef]

28. Colombo, E.; Marine, J.-C.; Danovi, D.; Falini, B.; Pelicci, P.G. Nucleophosmin regulates the stability and transcriptional activity of p53. Nat. Cell Biol. 2002, 4, 529-533. [CrossRef]

29. Vascotto, C.; Lirussi, L.; Poletto, M.; Tiribelli, M.; Damiani, D.; Fabbro, D.; Damante, G.; Demple, B.; Colombo, E.; Tell, G. Functional regulation of the apurinic/apyrimidinic endonuclease 1 by nucleophosmin: Impact on tumor biology. Oncogene 2013, 33, 2876-2887. [CrossRef]

30. Meyers, R.M.; Bryan, J.G.; McFarland, J.M.; Weir, B.A.; Sizemore, A.E.; Xu, H.; Dharia, N.V.; Montgomery, P.G.; Cowley, G.S.; Pantel, S.; et al. Computational correction of copy number effect improves specificity of CRISPR-Cas9 essentiality screens in cancer cells. Nat. Genet. 2017, 49, 1779-1784. [CrossRef]

31. Dempster, J.M.; Rossen, J.; Kazachkova, M.; Pan, J.; Kugener, G.; Root, D.E.; Tsherniak, A. Extracting Biological Insights from the Project Achilles Genome-Scale CRISPR Screens in Cancer Cell Lines. BioRxiv 2019. [CrossRef]

32. Herviou, L.; Kassambara, A.; Boireau, S.; Robert, N.; Requirand, G.; Müller-Tidow, C.; Vincent, L.; Seckinger, A.; Goldschmidt, H.; Cartron, G.; et al. PRC2 targeting is a therapeutic strategy for EZ score defined high-risk multiple myeloma patients and overcome resistance to IMiDs. Clin. Epigenet. 2018, 10, 121. [CrossRef] [PubMed]

33. Bret, C.; Klein, B.; Cartron, G.; Schved, J.; Constantinou, A.; Pasero, P.; Moreaux, J. DNA repair in diffuse large B-cell lymphoma: A molecular portrait. Br. J. Haematol. 2014, 169, 296-299. [CrossRef] [PubMed]

34. Moreaux, J.; Reme, T.; Leonard, W.; Veyrune, J.-L.; Requirand, G.; Goldschmidt, H.; Hose, D.; Klein, B. Gene expression-based prediction of myeloma cell sensitivity to histone deacetylase inhibitors. Br. J. Cancer 2013, 109, 676-685. [CrossRef]

35. De Boussac, H.; Bruyer, A.; Jourdan, M.; Maes, A.; Robert, N.; Gourzones, C.; Vincent, L.; Seckinger, A.; Cartron, G.; Hose, D.; et al. Kinome expression profiling to target new therapeutic avenues in multiple myeloma. Haematologica 2019, 105, 784-795. [CrossRef]

36. Wouters, B.; Löwenberg, B.; Erpelinck-Verschueren, C.A.J.; Van Putten, W.; Valk, P.; Delwel, H. Double CEBPA mutations, but not single CEBPA mutations, define a subgroup of acute myeloid leukemia with a distinctive gene expression profile that is uniquely associated with a favorable outcome. Blood 2009, 113, 3088-3091. [CrossRef]

37. Taskesen, E.; Bullinger, L.; Corbacioglu, A.; Sanders, M.A.; Erpelinck, C.A.J.; Wouters, B.J.; van der Poel-van de Luytgaarde, S.C.; Damm, F.; Krauter, J.; Ganser, A.; et al. Prognostic impact, concurrent genetic mutations, and gene expression features of AML with CEBPA mutations in a cohort of 1182 cytogenetically normal AML patients: Further evidence for CEBPA double mutant AML as a distinctive disease entity. Blood 2011, 117, 2469-2475. [CrossRef]

38. Taskesen, E.; Babaei, S.; Reinders, M.M.; De Ridder, J. Integration of gene expression and DNA-methylation profiles improves molecular subtype classification in acute myeloid leukemia. BMC Bioinform. 2015, 16, S5. [CrossRef] 
39. Hartlerode, A.J.; Scully, R. Mechanisms of double-strand break repair in somatic mammalian cells. Biochem. J. 2009, 423, 157-168. [CrossRef]

40. Wright, W.D.; Shah, S.S.; Heyer, W.-D. Homologous recombination and the repair of DNA double-strand breaks. J. Biol. Chem. 2018, 293, 10524-10535. [CrossRef]

41. D'Amours, D.; Jackson, S.P. The MRE11 complex: At the crossroads of DNA repair and checkpoint signalling. Nat. Rev. Mol. Cell Biol. 2002, 3, 317-327. [CrossRef] [PubMed]

42. Lee, J.-H. ATM Activation by DNA Double-Strand Breaks Through the Mre11-Rad50-Nbs1 Complex. Science 2005, 308, 551-554. [CrossRef] [PubMed]

43. Esposito, M.T.; So, C.W.E. DNA damage accumulation and repair defects in acute myeloid leukemia: Implications for pathogenesis, disease progression, and chemotherapy resistance. Chromosom. 2014, 123, 545-561. [CrossRef] [PubMed]

44. Uringa, E.-J.; Youds, J.L.; Lisaingo, K.; Lansdorp, P.M.; Boulton, S.J. RTEL1: An essential helicase for telomere maintenance and the regulation of homologous recombination. Nucleic Acids Res. 2010, 39, 1647-1655. [CrossRef]

45. Dong, S.; Han, J.; Chen, H.; Liu, T.; Huen, M.S.Y.; Yang, Y.; Guo, C.; Huang, J. The Human SRCAP Chromatin Remodeling Complex Promotes DNA-End Resection. Curr. Biol. 2014, 24, 2097-2110. [CrossRef]

46. Spivak, G. Nucleotide excision repair in humans. DNA Repair 2015, 36, 13-18. [CrossRef]

47. Hashimoto, S.; Anai, H.; Hanada, K. Mechanisms of interstrand DNA crosslink repair and human disorders. Genes Environ. 2016, 38, 9. [CrossRef]

48. Vonarx, E.J.; Tabone, E.K.; Osmond, M.J.; Anderson, H.J.; Kunz, B.A. Arabidopsis homologue of human transcription factor IIH/nucleotide excision repair factor p44 can function in transcription and DNA repair and interacts with AtXPD. Plant J. 2006, 46, 512-521. [CrossRef]

49. London, R.E. The structural basis of XRCC1-mediated DNA repair. DNA Repair 2015, 30, 90-103. [CrossRef]

50. Pietrzak, J.; Płoszaj, T.; Pułaski, Ł.; Robaszkiewicz, A. EP300-HDAC1-SWI/SNF functional unit defines transcription of some DNA repair enzymes during differentiation of human macrophages. Biochim. Biophys. Acta (BBA) Bioenerg. 2019, 1862, 198-208. [CrossRef]

51. Seedhouse, C.; Faulkner, R.; Ashraf, N.; Das-Gupta, E.; Russell, N. Polymorphisms in genes involved in homologous recombination repair interact to increase the risk of developing acute myeloid leukemia. Clin. Cancer Res. 2004, 10, 2675-2680. [CrossRef] [PubMed]

52. Jawad, M.; Seedhouse, C.; Russell, N.; Plumb, M. Polymorphisms in human homeobox HLX1 and DNA repair RAD51 genes increase the risk of therapy-related acute myeloid leukemia. Blood 2006, 108, 3916-3918. [CrossRef] [PubMed]

53. Li, C.; Liu, Y.; Hu, Z.; Zhou, Y. Genetic polymorphisms of RAD51 and XRCC3 and acute myeloid leukemia risk: A meta-analysis. Leuk. Lymphoma 2013, 55, 1309-1319. [CrossRef] [PubMed]

54. Wu, L.; Long, Z.; Dai, Z. 135G/C polymorphism in the RAD51 gene and acute myeloid leukemia risk: A meta-analysis. Genet. Mol. Res. 2016, 15. [CrossRef]

55. Allan, J.M. Genetic variation in XPD predicts treatment outcome and risk of acute myeloid leukemia following chemotherapy. Blood 2004, 104, 3872-3877. [CrossRef]

56. Pratcorona, M.; Brunet, S.; Nomdedéu, J.F.; Ribera, J.; Tormo, M.; Duarte, R.; Escoda, L.; Guàrdia, R.; De Llano, M.P.Q.; Salamero, O.; et al. Favorable outcome of patients with acute myeloid leukemia harboring a low-allelic burden FLT3-ITD mutation and concomitant NPM1 mutation: Relevance to post-remission therapy. Blood 2013, 121, 2734-2738. [CrossRef]

57. Lichtman, M.A. A historical perspective on the development of the cytarabine (7days) and daunorubicin (3days) treatment regimen for acute myelogenous leukemia: 2013 the 40 th anniversary of $7+3$. Blood Cells Mol. Dis. 2013, 50, 119-130. [CrossRef]

58. Murphy, T.; Yee, K.W.L. Cytarabine and daunorubicin for the treatment of acute myeloid leukemia. Expert Opin. Pharmacother. 2017, 18, 1765-1780. [CrossRef]

59. Bret, C.; Klein, B.; Moreaux, J. Nucleotide excision DNA repair pathway as a therapeutic target in patients with high-risk diffuse large B cell lymphoma. Cell Cycle 2013, 12, 1811-1812. [CrossRef]

60. Zhou, J.; Deng, Q.; Zhang, Y.; Tan, P.; Zhang, W.; Cui, H. CSN6 controls the proliferation and metastasis of glioblastoma by CHIP-mediated degradation of EGFR. Oncogene 2016, 36, 1134-1144. [CrossRef]

61. Gao, S.; Fang, L.; Phan, L.M.; Qdaisat, A.; Yeung, S.-C.J.; Lee, M.-H. COP9 signalosome subunit 6 (CSN6) regulates E6AP/UBE3A in cervical cancer. Oncotarget 2015, 6, 28026-28041. [CrossRef] [PubMed] 
62. Wen, D.; Liao, T.; Ma, B.; Qu, N.; Shi, R.-L.; Lu, Z.-W.; Wang, Y.-L.; Wei, W.-J.; Ji, Q.-H. Downregulation of CSN6 attenuates papillary thyroid carcinoma progression by reducing $\mathrm{Wnt} / \beta$-catenin signaling and sensitizes cancer cells to FH535 therapy. Cancer Med. 2018, 7, 285-296. [CrossRef] [PubMed]

63. Shaheen, M.; Allen, C.; Nickoloff, J.A.; Hromas, R. Synthetic lethality: Exploiting the addiction of cancer to DNA repair. Blood 2011, 117, 6074-6082. [CrossRef] [PubMed]

64. Curtin, N.J. Inhibiting the DNA damage response as a therapeutic manoeuvre in cancer. Br. J. Pharmacol. 2013, 169, 1745-1765. [CrossRef]

65. Kohl, V.; Flach, J.; Naumann, N.; Brendel, S.; Kleiner, H.; Weiss, C.; Seifarth, W.; Nowak, D.; Hofmann, W.-K.; Fabarius, A.; et al. Antileukemic Efficacy in Vitro of Talazoparib and APE1 Inhibitor III Combined with Decitabine in Myeloid Malignancies. Cancers 2019, 11, 1493. [CrossRef]

66. Nguyen, G.H.; Dexheimer, T.S.; Rosenthal, A.S.; Chu, W.K.; Singh, D.K.; Mosedale, G.; Bachrati, C.Z.; Schultz, L.; Sakurai, M.; Savitsky, P.; et al. A small molecule inhibitor of the BLM helicase modulates chromosome stability in human cells. Chem. Biol. 2013, 20, 55-62. [CrossRef]

67. Aggarwal, M.; Banerjee, T.; A Sommers, J.; Brosh, J.R.M. Targeting an Achilles' heel of cancer with a WRN helicase inhibitor. Cell Cycle. 2013, 12, 3329-3335. [CrossRef]

68. Toma, M.; Sullivan-Reed, K.; Sliwinski, T.; Skorski, T.; Toma Reed, S. RAD52 as a Potential Target for Synthetic Lethality-Based Anticancer Therapies. Cancers 2019, 11, 1561. [CrossRef]

69. Petroni, M.; Sardina, F.; Infante, P.; Bartolazzi, A.; Locatelli, E.; Fabretti, F.; Di Giulio, S.; Capalbo, C.; Cardinali, B.; Coppa, A.; et al. MRE11 inhibition highlights a replication stress-dependent vulnerability of MYCN-driven tumors. Cell Death Dis. 2018, 9, 895. [CrossRef]

70. Metzeler, K.H.; Hummel, M.; Bloomfield, C.D.; Spiekermann, K.; Braess, J.; Sauerland, M.-C.; Heinecke, A.; Radmacher, M.; Marcucci, G.; Whitman, S.P.; et al. An 86-probe-set gene-expression signature predicts survival in cytogenetically normal acute myeloid leukemia. Blood 2008, 112, 4193-4201. [CrossRef]

71. Huber, W.; Von Heydebreck, A.; Sültmann, H.; Poustka, A.; Vingron, M. Variance stabilization applied to microarray data calibration and to the quantification of differential expression. Bioinformatics 2002, 18, S96-S104. [CrossRef] [PubMed] 